\title{
ПРОБЛЕМЫ УПРАВЛЕНИЯ
}

DOI: $10.22394 / 2079-1690-2019-1-4-11-16$

\section{НОВАЯ МОДЕЛЬ ОРГАНИЗАЦИИ ПРОФЕССИОНАЛЬНОГО РАЗВИТИЯ ГОСУДАРСТВЕННЫХ ГРАЖДАНСКИХ СЛУЖАЩИХ КАК ФАКТОР ТРАНСФОРМАЦИИ ГОСУДАРСТВЕННОГО УПРАВЛЕНИЯ}

\begin{abstract}
Еварович
Светлана

Анатольевна

кандидат педагогических наук, вед. научн. сотр. научно-исследовательской лаборатории «Современные технологии в государственном управлении», зам. директора экспертно-аналитического центра государственной и муниципальной службы Института «Высшая школа государственного управления», Российская академия народного хозяйства и государственной службы при Президенте РФ (119571, Россия, г. Москва, пр. Вернадского, 82). E-mail: evarovich-sa@ranepa.ru

Готовщикова кандидат филологических наук, ст. научн. сотр. научно-исследовательской Наталья Эдуардовна лаборатории «Современные технологии в государственном управлении» Института «Высшая школа государственного управления», Российская академия народного хозяйства и государственной службы при Президенте РФ (119571, Россия, г. Москва, пр. Вернадского, 82). E-mail: gotovschikova-ne@ranepa.ru

Лаврова Татьяна Будаевна кандидат экономических наук, зав. научно-исследовательской лабораторией «Современные технологии в государственном управлении», директор центра современных технологий обучения и онлайн ресурсов Института «Высшая школа государственного управления», Российская академия народного хозяйства и государственной службы при Президенте РФ (119571, Россия, г. Москва, пр. Вернадского, 82). E-mail: batueva@ranepa.ru
\end{abstract}

\section{Аннотация}

В статье представлено описание базовых элементов новой модели организации профессионального развития государственных гражданских служащих, которая рассматривается как фактор трансформации государственной службы и государственного управления. Материалом исследования выступают научные данные отечественных ученых, нормативно-правовые акты, вступившие в силу в течение последних трех лет и методические материалы, разработанные Минтрудом России. На основе анализа документов выявлены направления развития формирующейся системы профессионального развития в контексте современных вызовов государственного управления.

Ключевые слова: государственное управление, государственная гражданская служба, модель организации профессионального развития, гражданские служащие, реформирование государственной службы, должностные регламенты, современные административные парадигмы, система профессионального развития, результативность профессиональной деятельности.

Проблемы развития государственной службы являются предметом научных дискуссий в нашей стране и за рубежом. Волна исследований последнего десятилетия в России во многом обусловлена стремлением провести анализ происходящих в публичном управлении изменений и определить факторы, формирующие вектор трансформации, который был задан программами реформирования и развития государственной службы, начиная с 2002 г. ${ }^{1}$

Многие авторы акцентируют внимание на взаимосвязи успешности реформирования государственной службы с эффективностью государственного управления, устойчивостью развития государства [1], [2], а изменение подходов к организации профессионального развития гражданских служащих рассматривают в качестве одного из факторов трансформации гражданской службы [3].

В настоящей статье - в контексте изучения проблемы модернизации гражданской службы и обозначения места и роли системы профессионального развития гражданских служащих в этом процессе - предпринята попытка ответить на ряд вопросов:

1) каковы задачи государственного управления на современном этапе развития общества?

2) каковы характеристики новой модели организации профессионального развития гражданских служащих, отвечающей современным вызовам, и в чем ее отличие от существовавшей ранее?

\footnotetext{
1 Федеральная программа «Реформирование государственной службы Российской Федерации (2003 - 2005 годы)»; федеральная программа «Реформирование и развитие системы государственной службы Российской Федерации (2009 - 2013 годы)»; федеральная программа «Развитие государственной службы Российской Федерации (2015 2018 годы)»; Указ Президента РФ от 24.06.2019 № 288 «Об основных направлениях развития государственной гражданской службы Российской Федерации на 2019 - 2021 годы».
} 
3) насколько формируемая модель соответствует заданному вектору трансформации государственного управления и гражданской службы?

Материалом исследования послужили научные данные отечественных ученых, нормативноправовые акты, вступившие в силу в течение последних трех лет, а также методические материалы, предложенные для применения в органах государственной власти Минтрудом России.

Обратимся к первому вопросу. Для понимания содержания и механизмов новой модели организации профессионального развития следует обозначить контекст современных вызовов и задач государственного управления. С позиции теории государственного управления, происходящие в мире изменения демонстрируют понятный тренд - «стремление к дебюрократизации управления, поиск новой модели исполнительной власти» [4].

По мнению исследователей, современный знаниевый, информационный этап развития постиндустриальности характеризуется появлением актуальной для государственного управления задачи создать для каждого человека возможности реализации собственного потенциала [5]. В этой связи в литературе употребляется термин «управление, основанное на знаниях», в который вкладывается идея о мобилизации «знаниевого» потенциала не только общества, но сотрудников аппарата управления [6].

Ученые сосредоточены на проведении глубокого анализа современных административных парадигм и моделей государственного управления для разработки механизма преодоления кризиса в государственном управлении, который сегодня переживают многие страны [7], [8]. Ряд авторов отмечают, что в России реформирование государственного управления и государственной службы в большой степени происходит в контексте «нового государственного управления» (New Public Management, или NPM). Данная парадигма государственного управления исходит из понимания сервисной роли государства (ориентации на качество оказания государственных услуг), целесообразности применения технологий бизнеса в государственном секторе. Среди инструментов, которые должны обеспечить эффективность, - сокращение расходов на государственный аппарат, реструктуризация; развитие законодательства о государственном заказе. В системе государственной гражданской службы речь идет о применении должностных регламентов, разработанных с учетом процессных показателей эффективности и являющихся основанием для оценки служебной деятельности (методология KPI) [8].

В научном дискурсе также выделяются аспекты технологической трансформации государственного управления. Как считают специалисты, для обеспечения конкурентоспособности государства в долгосрочной перспективе, расширения государственных сервисов и реализации принципов открытости в деятельности государственного аппарата, необходимо создание «системы организации и исполнения функций органов государственной власти, построенной на базе интегрированных цифровизированных процессов» [9, с. 7]. Кроме того, подчеркивается, что концепт «государства развития» является административным инструментом реализации курса «прорывного научно-технологического и социально-экономического развития», который был заявлен в мае 2018 г. Данный концепт предполагает превращение государственного аппарата и гражданских служащих в «администраторов развития», что обусловливает иные требования к качеству кадрового состава, организации кадровых процессов, включая систему профессионального развития гражданских служащих [10].

Таким образом, на основе анализа мнений ученых можно выделить следующие актуальные задачи государственного управления и государственной службы:

- мобилизация «знаниевого» потенциала гражданских служащих;

- превращение гражданских служащих в «администраторов развития»;

- внедрение «платформенного» подхода в государственное управление;

- обеспечение эффективности в деятельности гражданских служащих.

Все это в свою очередь формирует определенные требования к системе профессионального развития и той новой модели ее организации, которая создается в рамках реформирования гражданской службы.

В исследованиях, посвященных вопросам методологии профессионализации гражданских служащих, в качестве ключевой проблемы действующей модели обозначается слабая ориентация существующих программ и технологий профессионального развития гражданских служащих на компетенции должности и повышение эффективности и результативности профессиональной деятельности [3, с. 112].

Учитывая сказанное, при рассмотрении второго поставленного вопроса - о характеристиках новой модели организации профессионального развития гражданских служащих, - в качестве основных требований к такой модели, с нашей точки зрения, могут быть названы:

- возможность реализации потенциала гражданских служащих;

- оперативность в обновлении знаний и востребованных профессиональной деятельностью навыков;

- создание мотивационных условий для внедрения изменений гражданскими служащими при выполнении ими служебных обязанностей. 
Модель организации профессионального развития гражданских служащих как форма отображения данного кадрового процесса содержит существенные элементы: цель, принципы, этапы, формы и механизмы обеспечения профессионального развития, показатели эффективности и инструменты их оценки.

Для описания элементов новой модели перейдем к анализу нормативно-правовых актов, вступивших в силу в течение последних трех лет, а также методических материалов, предложенных для применения в органах государственной власти Минтрудом России.

Обновление подходов к организации профессионального развития гражданских служащих связано с осуществлением Плана мероприятий («дорожной карта») по реализации Основных направлений развития государственной гражданской службы на 2016-2018 гг. ${ }^{1}$ В рамках мероприятий «дорожной карты» были внесены существенные изменения в 62 и 63 статьи Федерального закона от 27 июля 2004 г. № 79-Ф3 «0 государственной гражданской службе Российской Федерации» (далее - ФЗ № 79).

Новеллами законодательства стали (статья 62 Ф3 № 79):

- введение понятия «профессиональное развитие» и расширение его содержания за счет включения, кроме дополнительных профессиональных программ (ДПП), иных мероприятий по профессиональному развитию;

- законодательное закрепление непрерывного, перманентного характера профессионального развития гражданских служащих;

- создание дополнительного инструмента осуществления дополнительных профессиональных программ - образовательного сертификата [11].

Таким образом, за счет введения в содержание профессионального развития, наряду с ДПП, иных мероприятий по профессиональному развитию, а также расширения оснований для принятия решения о направлении гражданского служащего на мероприятия по профессиональному развитию созданы условия для более оперативного реагирования на потребности государственных органов в обучении гражданских служащих. Кроме того, предложен новый организационно-финансовый инструмент индивидуального характера, который может способствовать удовлетворению индивидуальных запросов на ДПП, связанных с узкой спецификой профессиональной деятельности.

Нововведения коснулись также вопросов финансирования и планирования профессионального развития гражданских служащих:

- предусмотрено несколько вариантов финансирования мероприятий по профессиональному развитию: государственное задание, государственный заказ, средства государственного органа (в рамках требований и процедур Федерального закона от 5 апреля 2013 года № 44-Ф3 «0 контрактной системе в сфере закупок товаров, работ, услуг для обеспечения государственных и муниципальных нужд»), на основании именных образовательных сертификатов (статья 63 ФЗ № 79);

- изменен порядок формирования государственного заказа: ранее ответственность возлагалась на государственный орган, и требовалось согласование с соответствующим органом по управлению государственной службой, - теперь ответственность возлагается на соответствующий орган по управлению государственной службой. Порядок планирования предусматривает подготовку государственными органами заявок с учетом их функций и специализации, профессионального образования по должностям гражданской службы. Далее орган по управлению государственной службой на основе заявок формирует государственный заказ. Измененный порядок также может способствовать более оперативному и качественному планированию профессионального развития гражданских служащих.

Следующий этап в совершенствовании системы профессионального развития гражданских служащих связан с вступлением в силу Указа Президента Российской Федерации от 21 февраля 2019 г. № 68 «0 профессиональном развитии государственных гражданских служащих Российской Федерации» и постановлениями Правительства Российской Федерации от 18 мая 2019 г. ${ }^{2}$

В развитие норм Ф3 № 79 в рамках Положения о порядке осуществления профессионального развития государственных гражданских служащих Российской Федерации (далее - Положение), утвержденного Указом Президента РФ от 21.02.2019 № 68:

\footnotetext{
1 Указ Президента Российской Федерации от 11 августа 2016 года № 403; Распоряжение Правительства РФ № 1919-р «Об утверждении плана мероприятий («дорожной карты») по реализации Основных направлений развития государственной гражданской службы Российской Федерации на 2016 - 2018 годы", утв. Указом Президента РФ от 11.08.2016 № 403».

2 Постановление Правительства Российской Федерации от 18.05.2019 № 617 «0 признании утратившими силу некоторых актов Правительства Российской Федерации»; постановление Правительства Российской Федерации от 18.05 .2019 № 618 «Об утверждении Положения о прохождении служебной стажировки государственными гражданскими служащими Российской Федерации»; постановление Правительства Российской Федерации от 18.05.2019 № 619 «0 государственном образовательном сертификате на дополнительное профессиональное образование государственного гражданского служащего Российской Федерации»; постановление Правительства Российской Федерации от 18.05.2019 № 620 «Об утверждении Правил предоставления из федерального бюджета грантов в форме субсидий организациям, осуществляющим образовательную деятельность, в целях возмещения затрат, связанных с обучением федеральных государственных гражданских служащих на основании государственных образовательных сертификатов на дополнительное профессиональное образование».
} 
- расширено толкование термина «профессиональное развитие», которое заключается в приобретении гражданским служащим на системной основе новых знаний и умений, развитии его профессиональных и личностных качеств (п. 3 Положения);

- проведена градация «иных» мероприятий по профессиональному развитию в зависимости от цели участия в нем гражданских служащих: для ускоренного приобретения гражданскими служащими новых знаний и умений предлагаются семинары, тренинги, мастер-классы, иные мероприятия; для изучения передового опыта и обмена им предусмотрены конференции, круглые столы, служебные стажировки и иные мероприятия; поддержано развитие практики самообразования в рамках направлений профессиональной служебной деятельности посредством использования единого специализированного информационного ресурса;

- определена последовательность действий ответственных при планировании централизованного обучения федеральных гражданских служащих в рамках приоритетных направлений профессионального развития, а также реализации государственного заказа на мероприятия по профессиональному развитию и на осуществление обучения федеральных государственных гражданских служащих на основании образовательных сертификатов;

- предусмотрено использование федеральной государственной информационной системы в области государственной службы для осуществления контроля и учета мероприятий по профессиональному развитию федеральных государственных гражданских служащих.

Вместе с тем Положение не содержит упоминания об индивидуальных планах профессионального развития гражданских служащих и программах государственных органов по профессиональному развитию гражданских служащих. Таким образом, планирование профессионального развития гражданских служащих может осуществляться с использованием различных инструментов и подходов к планированию с учетом специфики кадровой политики исполнительных органов государственной власти. Положение также связывает результаты профессионального развития с процессами оценки профессиональной деятельности (в рамках аттестации) и должностного роста.

Итак, на основе анализа отдельных положений нормативно-правовых актов, регулирующих систему профессионального развития гражданских служащих, можно описать базовые элементы новой модели организации профессионального развития.

В качестве цели декларируется «поддержание и повышение уровня квалификации, необходимого для надлежащего исполнения должностных обязанностей государственными гражданскими служащими» (п. 3 Положения). Прослеживаются принципы построения новой модели: системность, непрерывность, ориентация на квалификационный подход, технологизация (цифровизация). Данные принципы заложены в различных положениях обновленного законодательства.

Этапы организации профессионального развития гражданских служащих описаны в Рекомендациях по организации дополнительного профессионального образования и иных мероприятий по профессиональному развитию государственных гражданских служащих Российской Федерации (далее - Рекомендации), которые были разработанным Минтрудом России в 2018 г. ${ }^{1}$

В тексте Рекомендаций уточняется цель мероприятий по профессиональному развитию: «обеспечить получение гражданскими служащими знаний и умений, позволяющих эффективно решать поставленные перед государственным органом задачи». Далее предлагается технология планирования данных мероприятий, включающая разработку ежегодного плана на основе анализа потребностей гражданских служащих и соответствующих ключевым направлениям деятельности государственного органа.

В Рекомендациях находит продолжение применение квалификационного подхода к организации кадровых процессов. В рамках процедуры планирования мероприятий профессионального развития рекомендуется использовать следующие целевые направления:

-получение предметных знаний и умений, необходимых для исполнения должностных обязанностей;

- развитие профессиональных и личностных качеств;

- получение знаний и умений в области технологий управления и стратегического планирования.

При этом гражданские служащие условно разделены на группы с учетом замещаемой ими должности государственной гражданской службы: «исполнители», «руководители среднего уровня», «руководители высшего уровня». Разработчиками предложены формулировки задач в области профессионального развития, а также алгоритм пошаговых действий при его планировании и подведении итогов.

Следует отметить, что Рекомендации являются логическим продолжением внедрения квалификационного подхода в систему кадровой работы и той модели профессиональных и личностных качеств, которые легли в основу Единой методики проведения конкурсов при замещении вакантных

\footnotetext{
1 https://rosmintrud.ru/ministry/programms/gossluzhba/16/3/3
} 
должностей и включении в кадровый резерв ${ }^{1}$. В перечень данных качеств включены: лидерские качества, стратегическое мышление, аналитические способности; коммуникабельность, управление конфликтами; умение формировать команду и работать в команде и др.

Таким образом, в основу механизма организации профессионального развития положен квалификационный подход, который в том числе содержит описание требований к профессиональным и личностным качествам (компетенциям). Принятие решения о направлении гражданских служащих на мероприятия по профессиональному развитию базируется на понимании специфики и задач профессиональной деятельности.

В качестве показателей оценки деятельности кадровых служб по организации профессионального развития предложены следующие процессы 2 :

- анализ потребности структурных подразделений в профессиональном развитии гражданских служащих (доля гражданских служащих, в отношении которых запланированы мероприятия по профессиональному развитию);

- формирование ежегодного перечня планируемых к проведению мероприятий по профессиональному развитию гражданских служащих по тематике, соответствующей основным направлениям деятельности федерального органа исполнительной власти (среднее число мероприятий на одного гражданского служащего);

- организация и проведение в федеральном органе исполнительной власти мероприятий по профессиональному развитию гражданских служащих (внутриведомственных семинаров, тренингов, мастер-классов, конференций, круглых столов, в том числе с привлечением представителей экспертного сообщества).

Методикой предусмотрены и соответствующие индикаторы: доля гражданских служащих, ежегодно участвующих в иных мероприятиях по профессиональному развитию; доля гражданских служащих, положительно оценивших результаты наставничества (оценивается через год после установления наставничества); доля гражданских служащих, удовлетворенных результатами освоения дополнительных профессиональных программ от общего числа гражданских служащих, прошедших обучение.

Данная методика оценки характерна для начального этапа становления новой системы, которая сосредоточена на задачах внедрения новых форм профессионального развития. Оценка эффективности мероприятий предлагается с позиции самих слушателей и пока не содержит показателей и индикаторов, которые позволили бы делать выводы о качестве работы с точки зрения практико-применимости.

Отвечая на третий вопрос, - насколько новая модель организации профессионального развития соответствует заданным трендам государственного управления, - в целом следует констатировать, что прослеживается внедрение менеджериального подхода, который сопровождается развитием механизмов оценки результативности и мониторинга.

На сегодняшний день созданы условия для более оперативного принятия решений о профессиональном развитии гражданских служащих, предложены адекватные формы профессионального развития, описана технология планирования и оценки данного кадрового процесса. Вместе с тем предложенное законодателями толкование цели профессионального развития лишь частично отражает требования нового этапа. Не явно прослеживается ориентация на решение перспективных задач государственного управления (готовность к выполнению роли «администратора развития»).

В отношении принципов обновленной модели организации профессионального развития возможна более четкая их артикуляция в качестве принципов в рамках текста Положения о порядке осуществления профессионального развития государственных гражданских служащих Российской Федерации или Рекомендаций Минтруда России. Кроме того, в контексте вызовов времени целесообразна декларация дополнительных принципов, связанных с трендами государственного управления.

Важным представляется исследование содержания деятельности гражданских служащих (по выделенным условным группам), предложенных требований в формате компетенций и современных задач государственного управления для возможной корректировки - так, на наш взгляд, необходимым является включение требований, связанных с готовностью гражданского служащего осуществлять профессиональную деятельность в условиях цифровой экономики и постоянных изменений.

\section{Литература}

1. Борщевский Г.А. В поисках оптимальной модели управления государственной службой (опыт российских регионов) // Государственное управление. Электронный вестник. Вып. 63. Август 2017. С. 67 - 98.

2. Кушлин В.И. Устенко В.С. Реформирование государственной службы как фактор управления социально-экономическим развитием (опыт развитых стран) // Современные технологии управления. 2015. № 5(53). С. $42-47$.

\footnotetext{
1 Постановление Правительства РФ от 31.03.2018 № 397 «Об утверждении единой методики проведения конкурсов на замещение вакантных должностей государственной гражданской службы Российской Федерации и включение в кадровый резерв государственных органов».

2 Методика оценки показателей повышения эффективности и результативности работы кадровых служб федеральных органов исполнительной власти, включая показатели эффективности использования кадровых peзервов. URL: https://rosmintrud.ru/ministry/programms/gossluzhba/16/strategy/1
} 
3. Меркулов П.А. Профессиональное развитие как элемент государственной политики повышения эффективности государственной гражданской службы // Вестник экспертного совета. № 1 (8). 2017. C. 107 - 112.

4. Оболонский А.В. Бюрократия: поисках новой модели// Общественные науки и современность. 2014. № 3. С. 5 - 22.

5. Мартынова С.Э. «Сервисная» модель муниципального управления в социологической интерпретации: Монография. СПб.: Социально-гуманитарное знание. 2015. 346 с.

6. Понкин И.В. Теория публичного управления: учебник для магистратуры и программ МРА / Институт государственной службы и управления РАНХиГС. М.: Буки Веди, 2017. 728 с.

7. Барабашев Г.А. Кризис государственного управления и его влияние на основные административные парадигмы государства и бюрократии // Вопросы государственного и муниципального правления. 2016. № 3. С. 163 - 194 .

8. Стрижов С.A. и др. Трансформация государственного управления в условиях новых вызовов: Монография / С.А. Стрижов, Е.А. Богатырева, Т.Г. Богатырева. М.: Изд-во «Проспект», 2018. 156 с.

9. Буров В.В., Петров М.В., Шклярук М.С., Шаров А.В. «Государство как платформа»: подход к реализации высокотехнологичной системы государственного управления. // Государственная служба. 2018. № 3. С. 6 - 17.

10.Слатинов B.В., Меркулов К.Г. Реформа бюрократии как условие становления «государства развития»: перспективы и ограничения модернизации государственной службы России // Среднерусский вестник общественных наук. 2019. Т. 14. № 1. С. 161 - 177.

11.Топильская А.Н., Трифонов Ю.Н. Система профессионального развития государственных гражданских служащих: новеллы законодательства и дальнейшие перспективы // Современное общество и власть (Электронный журнал). 2018. № 2 (16). С. 128 - 134.

Evarovich Svetlana Anatolyevna, PhD (Pedag.), Leading Researcher, Research Laboratory «Modern Technologies in Public Management», Deputy Director of Expert and Analytical Center for Public Service of the Graduate School of Public Management, Russian Presidential Academy of National Economy and Public Administration (82, Ave. Vernadsky, Moscow, 119571, Russian Federation). E-mail: evarovich-sa@ranepa.ru

Gotovshchikova Natalya Eduardovna, PhD (Philol.), Senior Researcher, Research Laboratory «Modern Technologies in Public Management» of the Graduate School of Public Management, Russian Presidential Academy of National Economy and Public Administration (82, Ave. Vernadsky, Moscow, 119571, Russian Federation). E-mail: gotovschikova-ne@ranepa.ru Lavrova Tatyana Budayevna, PhD (Econ.), Head of Research Laboratory «Modern Technologies in Public Management», Director of the Center for Modern Teaching Technologies and Online Resources of the Graduate School of Public Management, Russian Presidential Academy of National Economy and Public Administration (82, Ave. Vernadsky, Moscow, Russian Federation, 119571). E-mail: batueva@ranepa.ru

\section{NEW MODEL OF ORGANIZATION OF PROFESSIONAL DEVELOPMENT OF CIVIL SERVANTS AS A FACTOR OF TRANSFORMATION OF PUBLIC ADMINISTRATION Abstract}

The article describes the basic elements of a new civil servant professional development model, which is considered as a transformation factor of public service and public administration. The research material is the scientific data of domestic scientists, legal acts that have entered into force over the past three years, and methodological materials developed by the Russian Ministry of Labor. Based on the analysis of documents, the directions development for the emerging system of civil servant professional development in the context of modern challenges in public administration are identified.

Keywords: public administration, public civil service, professional development model, civil servants, public service reform, job regulations, modern administrative paradigm, professional development system, professional performance.

\section{References}

1. Borshchevskij G.A. V poiskah optimal'noj modeli upravleniya gosudarstvennoj sluzhboj (opyt rossijskih regionov) // Gosudarstvennoe upravlenie. Elektronnyj vestnik. Vyp. 63. Avgust 2017. P. 67 - 98

2. Kushlin V.I. Ustenko V.S. Reformirovanie gosudarstvennoj sluzhby kak faktor upravleniya social'no-ekonomicheskim razvitiem (opyt razvityh stran) // Sovremennye tekhnologii upravleniya. 2015. № 5(53). P. 42 - 47.

3. Merkulov P.A. Professional'noe razvitie kak element gosudarstvennoj politiki povysheniya effektivnosti gosudarstvennoj grazhdanskoj sluzhby // Vestnik ekspertnogo soveta. № 1 (8). 2017. P. 107 - 112.

4. Obolonskij A.V. Byurokratiya: poiskah novoj modeli// Obshchestvennye nauki i sovremennost'. 2014. № 3. P. 5 - 22.

5. Martynova S.E. «Servisnaya» model' municipal'nogo upravleniya v sociologicheskoj interpretacii: Monografiya. SPb.: Social'no-gumanitarnoe znanie. 2015. 346 p.

6. Ponkin I.V. Teoriya publichnogo upravleniya: uchebnik dlya magistratury i programm MPA / Institut gosudarstvennoj sluzhby i upravleniya RANHiGS. M.: Buki Vedi, 2017. 728 p.

7. Barabashev G.A. Krizis gosudarstvennogo upravleniya i ego vliyanie na osnovnye administrativnye paradigmy gosudarstva i byurokratii // Voprosy gosudarstvennogo i municipal'nogo pravleniya. 2016. № 3. P. 163 - 194.

8. Strizhov S.A. i dr. Transformaciya gosudarstvennogo upravleniya v usloviyah novyh vyzovov: Monografiya / S.A. Strizhov, E.A. Bogatyreva, T.G. Bogatyreva. M.: Izd-vo «Prospekt», 2018. 156 p.

9. Burov V.V., Petrov M.V., SHklyaruk M.S., SHarov A.V. «Gosudarstvo kak platforma»: podhod k realizacii vysokotekhnologichnoj sistemy gosudarstvennogo upravleniya // Gosudarstvennaya sluzhba. 2018. № 3. P. 6 - 17.

10. Slatinov V.V., Merkulov K.G. Reforma byurokratii kak uslovie stanovleniya «gosudarstva razvitiya»: perspektivy i ogranicheniya modernizacii gosudarstvennoj sluzhby Rossii // Srednerusskij vestnik obshchestvennyh nauk. 2019. T. 14 . № 1 . P. $161-177$.

11. Topil'skaya A.N., Trifonov YU.N. Sistema professional'nogo razvitiya gosudarstvennyh grazhdanskih sluzhashchih: novelly zakonodatel'stva i dal'nejshie perspektivy // Sovremennoe obshchestvo i vlast' (Elektronnyj zhurnal). 2018. № 2 (16). P. 128-134. 